\title{
Thinking Processes as a Tool for Improving the Administrative Process
}

\author{
García-Vidal Gelmar, Sánchez-Rodríguez Alexander, Martínez-Vivar Rodobaldo, Pérez-Campdesuñer \\ Reyner \\ Faculty of Administrative Sciences, Equinoctial Technological University, Santo Domingo, Ecuador
}

\begin{abstract}
The aim of this paper is to design an organizational strategy for improving administrative processes of Yonyum Company. For that, a diagnosis of the current situation of the company was made in Yonyum Company. For collecting information from employees of the organization, an analytical "thought processes" tool was used as an essential tool of research. This research was taken to design a strategy for improving the administrative processes of Yonyum Company. The strategy developed for the company consists of several actions formulated inferring from the problems identified through the investigation.
\end{abstract}

Keywords: Administrative process, Strategy, Continuous improvement, Thinking processes

\section{Introduction}

In the current context of organizational development, a strategy, understood as "the response of an organization to its strategic challenge" (Bueno Campos and Salmador Sánchez, 2000, p.2), maintains its leading role in the current administration to promote changes that will lead to the improvement of the organization. In this respect, the attention should be paid to both the design process and the obtained product strategy or content of the strategy. One of the critical tasks of management is to find a consistent way of designing strategies that promote significant changes in their organizations (Bueno Campos and Salmador Sánchez, 2000).

Yonyum Company is dedicated to the transformation of banana into banana chips, a snack that is consumed by various market segments. Production of banana chips makes the company a very desired in the town of El Carmen and it stands out in the market of the same product. This organization is located at $41 \mathrm{~km}$ of Chone Road next to the exit of the bypass in El Carmen - Manabí. There is a large production of raw banana in this area. Company's location in this area facilitates access to this raw material for the production of snacks being distributed nationally and internationally. In the organization, there is a need for improving administrative processes work to increase current performance levels. Through interviews with managers, we were able to identify the main symptoms related to the performance of the organization as given below:

The enterprise's growth is limited: Yonyum Company's main objective is the commercial expansion. There are several factors hindering the company's intention to expand. One of them is economic limitation; insufficient income to risk investing in machinery. Another hindering factor is the high cost of hiring new employees. Even current employees are quite heavy burden within operating expenses of the company. The organization is strategically limited and this affects different areas of the company. In the administrative part, there is a lack of participation of all actors who might well collaborate with their views in planning the company. Regarding the production area, there is an impairment caused by the lack of organization. Especially, the "control" is there the most agonizing process.

The dissatisfactions of employees: Another drawback affecting the company is that they are not formalized with the responsibilities of employees causing a lack of control to employees. This informality in office people get end up affecting productivity of the company and in turn can generate an emotional imbalance in the normal business development of the company. 
In addition, it is identified that employees are not fully satisfied by factors of personal growth, remuneration and motivation received. There are several things that influence negatively on the performance of staff thereby affecting equally the ability the company operation. All these move to the costs covered by the company. The importance that organizations attach to employee motivation is perceived by the effort and resources that company invest to teach and train employees and also train managers in order to motivate their employees. All of these are well reflected in the literature (García Sotomayor, 2012). Employees of the organization carry out their work by their own and family welfare. Although they enjoy a stable job, they show deterrents for other issues such as the need to improve their work experience due to lack of training and low participation and confidence in the company and other factors that give them an intrinsic motivation.

No targets are met in time and with the required quality: Failure to comply with the objectives causes economic stagnation of the company. The company has a deficiency in the administrative function of control and measuring effectiveness standards of workers. In addition, due to the lack of organization and coordination, workers waste valuable time giving a slowdown in the growth of the company. Company does not take into account the need to control the deviations that often occur in the activities of each employee or it not correctly done. The company suffers to monitor the process of implementation of activities that have been programmed to diagnose what is lagging or failing in this process. Lack of monitoring these activities ends up diverting unconsciously and delay the long-term target. From all analyzed, the absence of a strategy for improving administrative processes in Yonyum Company is found.

\subsection{Improving organizations}

The improvement represents an opportunity. Taking advantage of the creativity of all staff of the organization, not just a handful of specialists, it is possible to become much more innovative. The improvement can be used to drive performance in any of the edges of the business (for example, administrative processes, costs, quality, work organization, etc.) through staff involvement (Bessant, Caffyn, Gilbert, Harding, and Webb, 1994; Fukada, 1990).

In today's hectic business environment, organizations are seeking improvements for products and services offered and production methods thereof (Gallagher and Austin, 1997; Robinson, 1991), but for all of these improvements, there is a need to first enhance administrative processes responsible for setting goals, standards of behavior, motivations and feedback control in the organization. Whether these improvements are developed through an occasional discovery or radical, or by gradual improvements and adjustments or smaller type of innovation, organizational change is essential not only to remain competitive but also to survive in the business.

The improvement is a generic term for a range of activities designed to achieve a high degree of involvement of employees in innovations. Actually, it is an umbrella term for an organizational policy (high involvement) supported on a range of specific tools. As this is a basic approach, it is often linked to more specific change programs, for example, business process reengineering, total quality management or different versions of the concept of "adjusted". In each case, the contribution of the improvement is to maintain and expand progress through a regular flow of small improvements. Process improvement is associated with gradual innovation focused and sustained for the entire company. It seems very simple, but its involvement is a bit more complex. The factors involved in MC are represented graphically in Figure 1.

Despite the intention of improving, its implementation is necessary to have the required impact on the organization. "The implementation model is based on the development of certain set of behaviors that must be learned and strengthened routinely. Companies develop these skills or routines, and associated behaviors by obtaining a particular impact on performance. This suggests that the development process of continuous improvement is evolutionary" (Marin-Garcia, Bautista - Poveda, and Garcia-Sabate, 2014, p. 589).

In the literature (Bessant, Caffyn, and Gallagher, 2001; Garcia-Sabater and Marin-Garcia, 2011), there is a model that structures the implementation of continuous improvement in five levels. Each of these levels takes time, and there is no guarantee that the organizations can progress to next level. In the words of Bessant et al., (1994), moving forward means finding ways to overcome specific obstacles that are associated with different phases. 


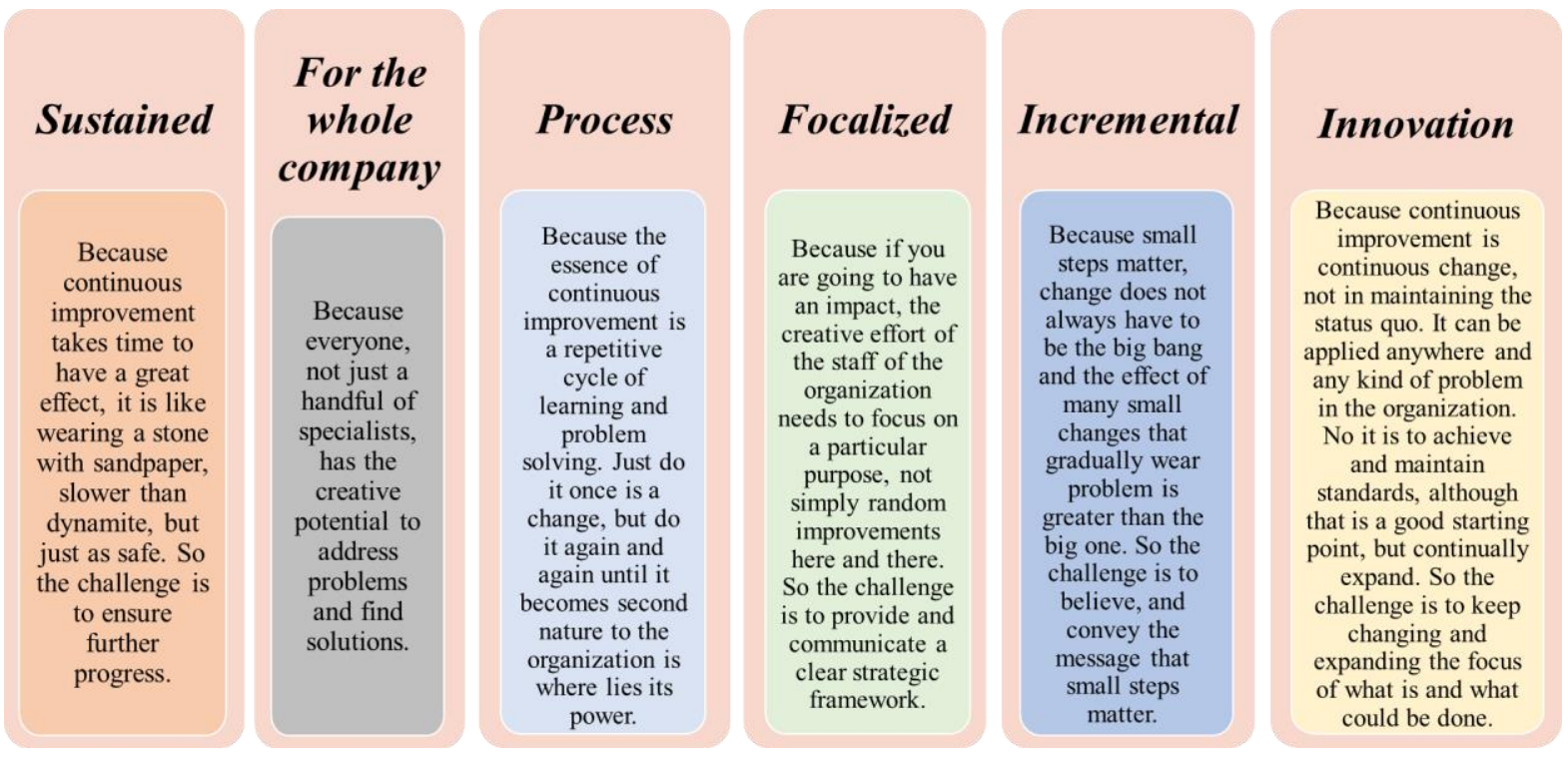

Figure 1: Factors involved in the improvement

In this research, improvement philosophy called "Thinking Processes" (Goldratt, 1995; Goldratt and Cox, 1993) will be followed. It is based on the Socratic teaching method and has three steps expressed in questions: What change, where we want to reach and how to induce the change? (Taylor and Ortega, 2003; Valle Antunes, Klippel, Koetz, and Pacheco Lacerda, 2004 ).

This type of mental exercise builds and communicate common sense forcing verbalize hunches, and so, really release the intuition and the ability to verify (Goldratt, 1995). Well-thought processes help build a comprehensive and implementable solution for the primary business of the organization. There are several works which provide reviews of "Theory of Constraints" (Cox and Spencer, 1998; Dettmer, 1997; Kendall, 1998; Mabin and Balderstone, 1999; McMullen, 1998; Noreen, Smith, and Mackey, 1995). Central to "Theory of Constraints", was that any organization has a constraint or a small number of constraints which rule the entire system. The central proposition consists of concentrating all efforts on the called core problems, that is, the problems that impact the global system performance in a significant way (Valle Antunes, et al., 2004 ). The secret to success lies in managing these constraints and restructure the rest of the organization around it (Tulasi and Rao, 2012). The major component of "Theory of Constraints" is that it reinforces all the other parts of the methodology of "Thinking Process" that include a suite of five logic diagrams (four trees and a "cloud") and a set of logical rules. "Thinking Process" tools offer a meticulous and systematic means to address identification and resolution of unstructured business problems based on the systemic use of the logical relationships of cause-effect, necessity and generalization; so once acquired they result easy to handle and to understand. In an extension of "Thinking Process" application tools, several authors have begun to experiment with the use of the tools for analyzing and formulating strategy (Chou, Lu, and Tang, 2012; M. C. Gupta, Boyd, and Sussman, 2004; Klein and Debruine, 1995; Schragenheim and Dettmer, 2000; Taylor and Ortega, 2003; Watson, Blackstone, and Gardiner, 2007). "Theory of Constraints" using "Thinking Process" is helpful in identifying a strategic direction for transforming an undesirable state into a desirable future facilitating changes in management (Cox, Blackstone, and Schleier, 2003; Chou, et al., 2012; M. Gupta, 2003; M. C. Gupta, et al., 2004).

The first question points to the root problem of organization that produces the greatest amount of undesirable effects within it. To get to identify this root problem, the first instrument or "Current Reality Tree" is built, starting from the undesirable effects and through the connection between them. This process allows clearly identify the problem sought.

The second question is answered by presenting precisely the conflict that is causing the root problem and address searching and building a solution through the confrontation of the implicit assumptions. This discovery (the solution), which is the second instrument, can in turn have the catalyst that will cause the replacement of existing undesirable effects by the desirable effects being careful not to create new undesirable effects eithers. This tool is called "Future Reality Tree", which is the third instrument. During this process, people learn to verbalize solutions that can evaporate 
the root problem, present a conflict without pointing blame, finding hidden behind an argument. In the process, this eliminates existing problems without creating new assumptions.

The third question leads to the construction of "Prerequisites Tree", fourth instrument aimed at determining interim targets to be established to identify obstacles that can arise when implementing the solution found. The process intends to use the obstacles as motivational levers to act through drawn intermediate markers to divide the task of implementing the solution in a set of interrelated and well-defined intermediate targets. This tree will be followed by the fifth instrument. "Transition Tree" is simply building a logical plan implementation entirely based on concrete undertaking aimed at removing obstacles, providing skills to convert strategy into achievable tactical actions, effective and immediate results (ÁlvarezLópez, Zayas Miranda, Pérez Campaña, 2004).

This thought process generally provides the ability to use "Theory of Constraints" in an easy and consistent manner that allows the administrative process accessible to any executive. Both methods facilitate the administration to develop a continuous process in search of increased goal and indispensable condition which means a constant improvement for the organization.

These methods are expressed in a spiral of continuous improvement, but an improvement, (Goldratt, 1995; Goldrattand Cox, 1993), that is aimed at breaking the few restrictions that govern the level of overall performance.

\section{Methodology}

For this research, a mixture of the exploratory and descriptive approach will be developed. The exploratory study seeks to establish the diagnosis of the current situation of the object of practical study through the characterization of the elements of its business philosophy, environment, and issues affecting the administrative process, internal operating elements, and their economic situation. Descriptive research (Reyes Martínez, 2009) will allow the description of the undesirable effects associated with the administrative processes and the interplay between them, which will facilitate the development of the strategy for improvement.

The method of experts for the development of thought processes (Goldratt, 1995) through various sharing sessions that will build the tools associated with administrative tool that allows the design of the strategy for improvement of administrative procedures will apply. Thought processes: (1) focus and verbalize the various situations that facilitate people, (2) allow you to build and communicate common sense and (3) allow focus on solutions based on the critical issues of the organizations (regardless of size or money), and a set of tools to implement it, as an element for improving administrative processes.

Morphological analysis (Zwicky, 1969) will be used to explore all possibilities to a particular system that can evolve as a result of an internal or external intervention. In this vein, the Morphological Analysis (Arapé, 2000) is concerned with the development of practical applications that allow us to discover and analyze the structural or morphological interrelations between phenomena, objects or concepts; in order to use the results in the construction of new systems or display of new forms in social, economic and political systems (organizations).

\subsection{Specific Methodology}

The proposed methodology has the general objective to design a strategy for improving administrative processes in Yonyum Company. In the use of this methodology, following steps, methods and tasks are linked together to be developed in conducting the research (Figure 2):

\section{Step 1: Characterization of the Organization}

The objective is to characterize the organization. This step is considered necessary to make a characterization of the company where the specific methodology is applied. This characterization must contain basically the following items (Noda Hernández, 2004); methods and tools, document review, Porter's 5 Forces (Porter, 1980).

\section{Step 2: Identification of the undesirable effects associated administrative processes}

The objective is to identify the greatest number of undesirable effects associated with administrative processes. Based on the implementation of the exploratory survey, a presentation highlighting the results achieved undesirable effects identified with such instruments, which facilitates the start of using the different tools that make up what is known as 
Thinking Processes tool. The development of thought processes requires the work of the experts. The facilitator of this process must be prepared before a person starts the group activity.

In this particular step, it will draw up a Current Reality Tree (CRT) representing the diagram of the cause-effect relationships that connect all undesirable effects (UE) identified in administrative processes. Once this is done, person may notice that there is no struggling with many problems at the root because there are almost always one or two independent causes. To create a more effective improvement process, one must look for those elements that cause most existing undesirable effects on the problem. The fewer root causes are identified as responsible for the undesirable, more accurate and powerful effects will be the improvement process. If it is agreed that an undesirable effect is usually only a symptom - effect resulting from a root problem - then it is obvious that the search for the root problem must be based on the cause - effect relationships. Therefore, person should take time to build a CRT that is the logical picture of a problem.

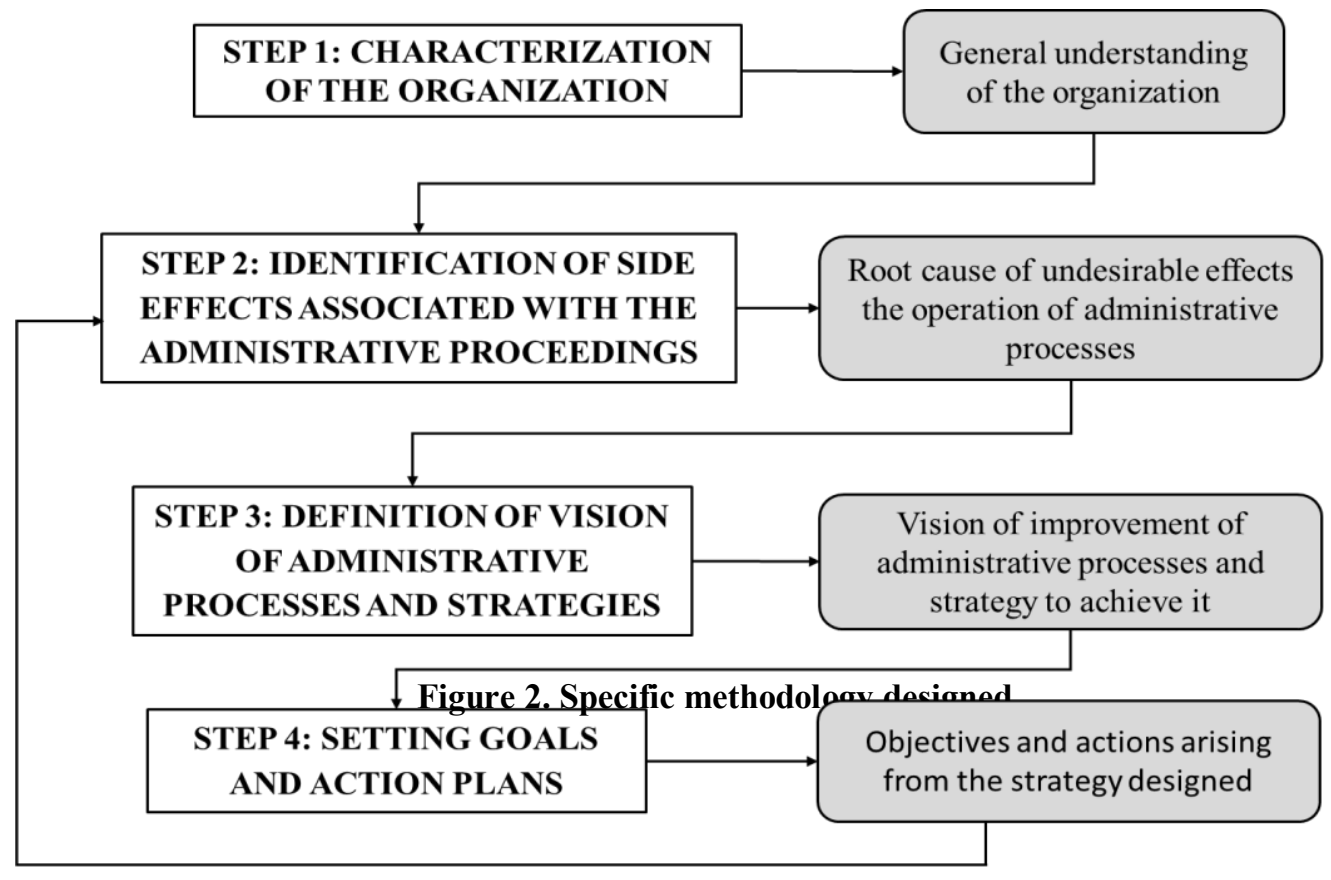

Step 3: Defining the vision of administrative processes and strategies (Methods and tools: Survey Group Work, Brainstorming, CRT (Goldratt, 1995))

The objective is to define the vision of improving administrative processes, strategies to achieve qualitative and transit of these towards achieving the vision. The vision is understood as a general statement that defines the future state that is wanted to be achieved. Administrative processes are defined to achieve an approach to change person's current situation. It is a consequence of the root problem that prevents change. The vision sets the opposite to overcome the root problem identified in the CRT. Once declared, the vision must become the fundamental objective until root problem is changed at which attention must be reformulated in generalities exposed to them before (García Vidal, 2006). Possible methods and tools to use: Group Work, Brainstorming (Calviño, 1988; Marenco, 1995), Evaporating Cloud, Future Reality Tree (FRT) (Goldratt, 1995).

\section{Step 4: Setting goals and action plans}

The objective is to identify obstacles to the implementation of the strategy and define the steps to be taken. Based on the vision and strategies defined to achieve it, you need to implement each of them. The FRT has shown that once implemented, strategies achieve the desired result: the opposite, target the root problem (vision). The implementation of the strategies is not an easy task. Do not forget that one of these strategies are an important discovery that departs from the traditional ways of solving problems, for this reason, generally, the implementation should be subdivided into smaller steps. For this the Tree Prerequisites (TP) is constructed. Possible methods and tools to use: Group Work, Brainstorming (Calviño, 1988; Marenco, 1995), Transition Tree, Tree Prerequisites (Goldratt, 1995). This step completes the exposure of the specific methodology designed; the figure below shows the logic of the steps to be implemented. 


\section{Results}

The results of the application of the specific methodology proposed in Yonyum Company Canton El Carmen in Ecuador are presented.

\section{Step 1: Characterization of the Organization}

In response to the specific methodology proposal, it proceeds to characterize the practical purpose of the investigation. Yonyum Company is an organization dedicated to the transformation of banana in banana chips, a snack which is consumed by various market segments, making it a very desired product that meets all quality requirements demanded by the market in the town of Carmen and outside it.

While it is true that the step that develops is limited to the characterization of the object of practical study, it is necessary to express an opinion on the above-mentioned elements:

1. There are problems in drafting the mission and vision, despite the multiple views in the literature, it appears that it could be presented as mission vision and vice versa.

2. The mission suffers from some of the essential criteria by which the writing of this component of the philosophy of a company is oriented.

3. The vision even with the previous remark does not narrow over time so it cannot determined when reached.

4. The stated objectives do not meet the requirements for processing, quantifiable, measurable, and time-bound.

The elements outlined above envision deficiencies in the administrative processes of the company studied. Today the company makes deliveries to twenty retail stores, three supermarkets medium and high consumption (distributor Scorpio, distributor Economy and distributor of consumer massive Proint: Supermarkets La Favorita, Warehouses TIA, Supermarkerts AKÍ, Supermarkets Santa Maria), because toys, sweets, Christmas arrangements are the largest consumed products by Christmas and New Year season. Other target markets are cevicheras and restaurants, where it has a distribution line chifles the bulk (pomas). Among the cities with the highest consumption of banana chips Yonyum, are El Carmen, Santo Domingo, Quito, Cuenca, Loja, Guayaquil, and coastal areas such as Pedernales, Salinas, Atacames, Esmeraldas, and others. In the city of Carmen there are many banana packing plants but very few that process chifle in the city. However, Bananas Rogai company is among the major competing companies that can influence local consumers. It is an Ecuadorian company dedicated to the production, marketing and distribution of chifles; Prodalec Cia Ltda, dedicated to the production of snacks - green, mature and cassava as well as other varieties such as plantains, and maquila for brands chifles; Aguita S.A: Processing Company cassava, taro, banana (in banana chips or peeling and packaging) for export to anywhere in the world. For the strategic diagnosis we decided to use the instrument of Porter's 5 forces which yielded the following results:

\subsection{Threat of entry of new competitors}

As the city of Carmen is agricultural and the area produces lots of banana, the threat of new competitors is real because of the low cost of raw materials has led to business groups and entrepreneurs to consider the creation of new industrial enterprises in this category positively. It is necessary to add to the above that the resources needed to start a business of this type are not high which a major barrier for entering a sector is.

In addition, the product is not difficult for the differentiation, so that customers would not face the costs of switching suppliers; access to distribution channels no difficulties subject to compliance with established standards. Possible cost advantages that could have established companies for ownership of the technology, the know-how of the product, favorable access to raw materials, favorable location, government subsidies, the experience of the workforce, etc., they do not constitute a barrier so they can get new companies to compete. On the other hand, there are no government regulations that prevent insertion in this market; however, the transformation of the productive composition of the country is encouraged taking advantage of the natural and cultural riches of the region. All this makes that there are no barriers to entry to important sectors to discourage the existence of new competitors.

\subsection{Threat of entry of substitute products}

The products that replace the banana do not occur in the area, but there are a variety of different snacks such as potatoes, chitos, popcorn; on the other hand, as the market grows wider range offers national and import level. In addition to the above, it is possible to say that the prices are not relatively similar and do not imply a psychological cost 
higher purchase as there is availability in the market due to the wide variety of suppliers that join this high propensity of consumers to experience new offers on the market.

Taking into consideration the above stated, is possible to say that the threat of entry of substitute products is high because there is not only an offer that is presented as an alternative to the buyer, but sometimes significantly improves the price or performance of the product in question as they are lower in fat or used for healthier products processing.

\subsection{Bargaining power of suppliers}

The main supplier is the company "La Fabril" to be the leading provider competitive pricing and relationships are good and has reached important agreements, so that even when a single supplier is considered that there is a balance of power. There are other providers in the agricultural sector. However, as there are many potential suppliers in the industry, it is considered that they have low power. It should be taken into account that the analyzed company has developed a backward integration because it has a farm where it provides the raw material needed to produce its bid for what goes to suppliers of bananas only when its production is not enough to develop market orders.

\subsection{Bargaining power of consumers}

Consumers are the most dangerous threat because they depend on the company also chifle negotiate the price of which varies in winter and summer. Companies should consider consumers' behavior because they are sensitive to a change in the price, and there are many providers could easily switch to competitors that offer the same snacks or substitute products, giving the above bargaining power to clients.

\subsection{Rivalry among competitors}

There are several companies like Bananas Rogai, Prodalec Cia Ltda., and Aguita S.A. dedicated to the production of banana chips with different strategies, backgrounds and personalities managed by the owners themselves, this makes them quite similar to each other, so that the experience of the behavior of the companies in this situation, some of the competitors could cut prices in a very aggressive way to get an advantage over others. Especially considering that the price of the raw material is regulated by the same competitors as the city of El Carmen is highly agricultural and supply banana barraganete is greater than demand except in summer when low banana production.

Similarly, it was observed that fixed costs are highly relative to the total value of the manufactured product; this makes companies being subject to great pressure to produce at full capacity in order to maintain the low unit costs. The product is offered to the market by the companies competing regarded as a commodity on which the buyer has several options, and the cost faced by the buyer by changing brand or supplier is small. All this makes the rivalry between competitors is high. The previously mentioned elements are summarized in Figure 3.

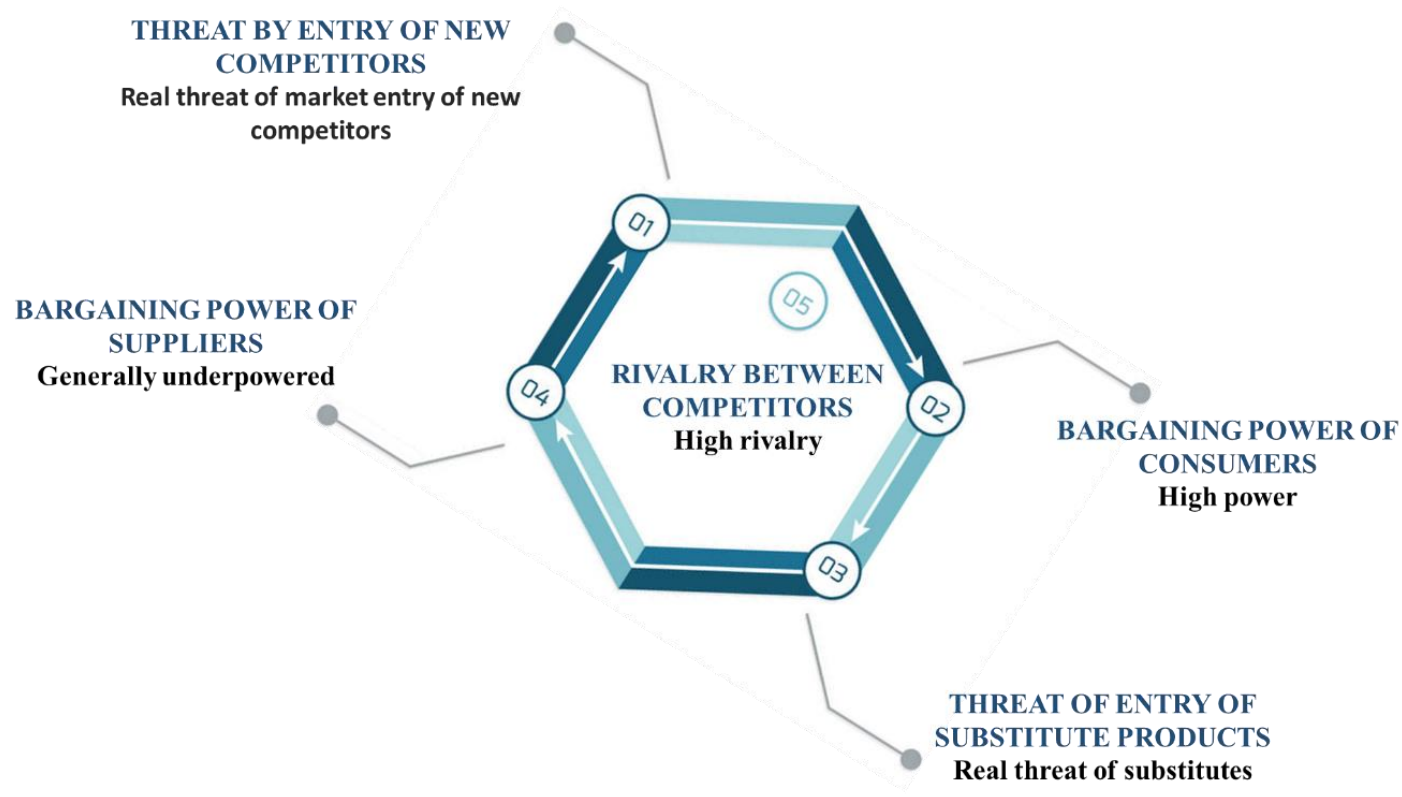

Figure 3: Diagram of force involved in business 
Once the five forces of the industry are analyzed, it could clearly identify the critical success factors, which are the elements that should have any company wishing to compete in that industry. In the particular case being analyzed, it is possible to say that the company should promote the improvement of its processes, the element, which so far has not managed to obtain, so work in this direction will set you both objective and plans future action to achieve in order to have a less vulnerable strategic position. If they cannot be met, better leave that sector since their chances of profitability are virtually nil.

Step 2: Identification of the undesirable effects associated administrative processes

To identify undesirable effects related to administrative processes a survey conducted on the basis of the review of similar studies (Bullones Álvarez, 2008; Vela Zuñigaand Ruiz Garzón, 2006) was applied to the six members of the company, the survey consists of four large groups that match the four administrative process, planning, organization, management and control, it was directed to identify whether the most essential elements within each of them were satisfied and sought to assess the presence of these in the organization studied. The survey had 28 questions in all categories of dichotomous responses tailored to the needs of information to which people wanted to respond. Having a very small sample was not possible to analyze the reliability of the survey. However he underwent an analysis of content validity were used 10 experts specialists obtaining a result of Index Content Validity Total 0, 69 value is above 0,62 established for this number of experts (Law she, 1975). With the above results, it can be said that the survey can be applied and the results to be obtained from it will measure what is intended. In the overall results of the questionnaire, it was verified that planning and control are processes that require an improvement plan since the associated questions were identified as problematic is applied.

To meet the objective of this step of the methodology used was necessary the creation of a working group composed of management and employees of the company guaranteeing basic training in techniques of group work, all this with the aim of ensure commitment to join the group and to generate the necessary actions to achieve the commitment of other workers. Working with the group began with actions of information on the situation of administrative processes previously identified and steps so far had developed in the research, its results and lessons learned. A gradual, incremental and steady process of awareness of management and employees was also launched, with regard to the need to improve administrative processes, in order to contribute to the present and future performance of the company.

The researchers acted as facilitators of this process in the development of group activity, and work plan included:

1. Objective: To find the relationship between the undesirable effects to identify the root cause.

2. Methodology: the logic of thought processes describing the various instruments that comprise explained. With auxiliary materials such as: flipcharts, markers and post-it.

3. Time available: a working session of two hours.

This serves as a preparation phase; with the process being is of vital interest to secure the commitment and participation of those involved starts. The working group as an initial task performed an analysis of the information provided to them in addition to the initial reflections on the findings so far, on administrative processes and overall performance of the company.

The problems highlighted exploration conducted, were reworked in statements that made the list of the main problems currently affecting administrative processes, ie, undesirable effects; these are the elements that analysis will give rise to the current reality tree that will support to identify what is causing these effects is done. Following the logic of behavior explained in the specific methodology, preceded to the construction of the Current Reality Tree in which relations between the undesirable effects may be visible. Said Current Reality Tree is seen in Figure 4.

Then you will be visualized the relations established by the group members could identify the root cause of undesirable effects related to administrative processes, and this is the "absence of a strategic approach to administrative processes."

Step 3: Defining the vision of administrative processes and strategies

For the definition of the vision understood as the opposite of the problem or root cause to overcome identified in the CRT Cloud to visualize the conflict in the company and formulate a strategy or injection that allows breaking and thus facilitating the improvement process was built administrative processes and with it build the future reality tree. 
Likewise, the researcher served as facilitator of this process in the development of group activity, and work plan included:

1. Objective: Build the Cloud, formulate strategy and build the Current Reality Tree.

2. Methodology: procedure for the construction of the Cloud and Current Reality Tree. With auxiliary materials such as: flipcharts, markers and post-it.

3. Time available: two working sessions of two hours.

Following the work plan established the group consisting of members of the company they developed the established procedure. The results achieved are presented. Figure 5 shows the construction and evaporation of the cloud.

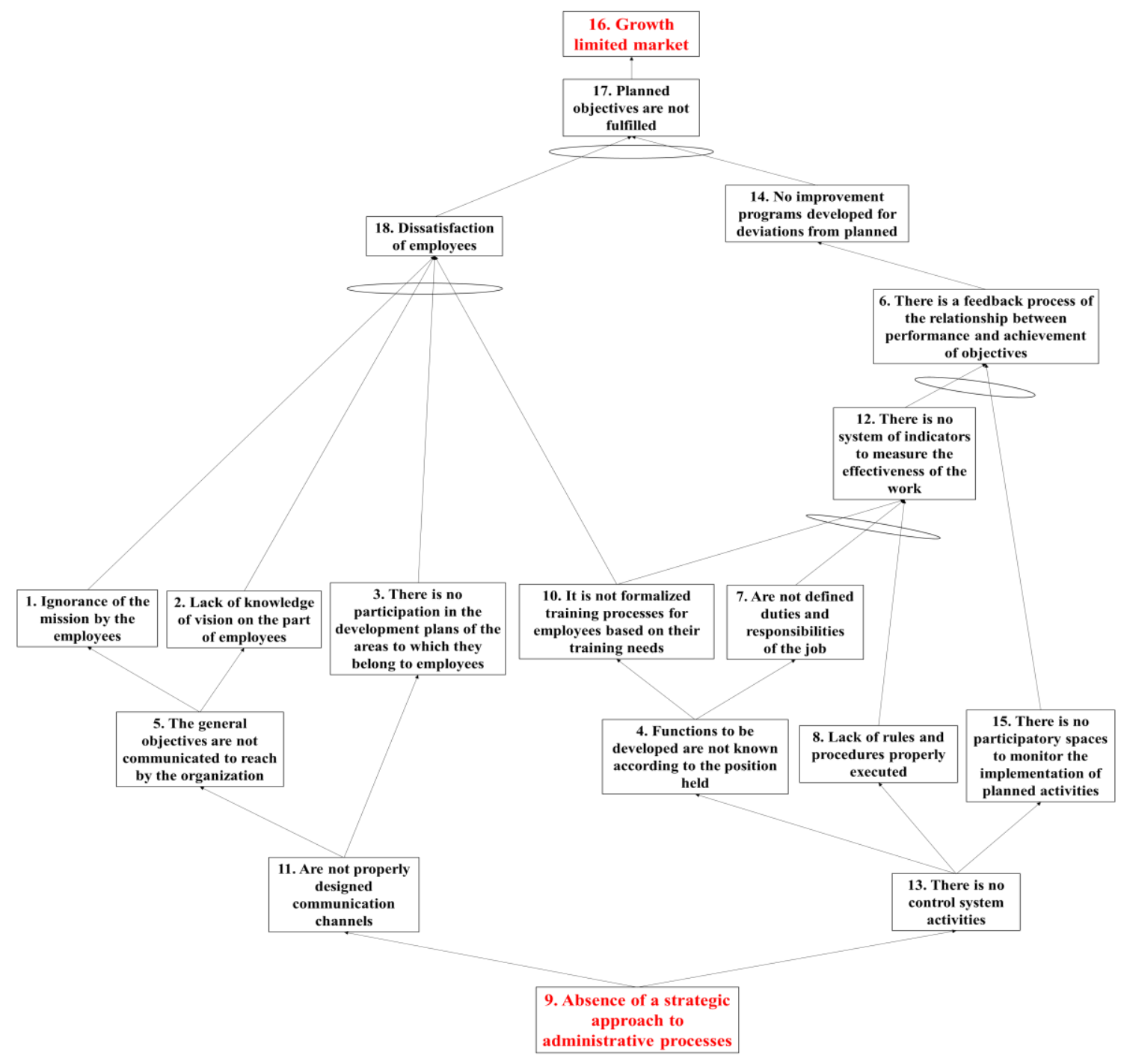

Figure 4: Current Reality Tree

After identifying the main conflict, the strategy has been formulated as: "Designing an organizational strategy for improving administrative processes of Yonyum Company." The strategy formulated allowed the construction of the Future Reality Tree (Figure 6) where the vision of the organization in terms of administrative processes once the formulated strategy is applied is displayed. The effect of the implementation of the strategy results in a series of desirable effects that lead to achieving the objective expected the strategic approach of administrative processes, which will improve their performance. 


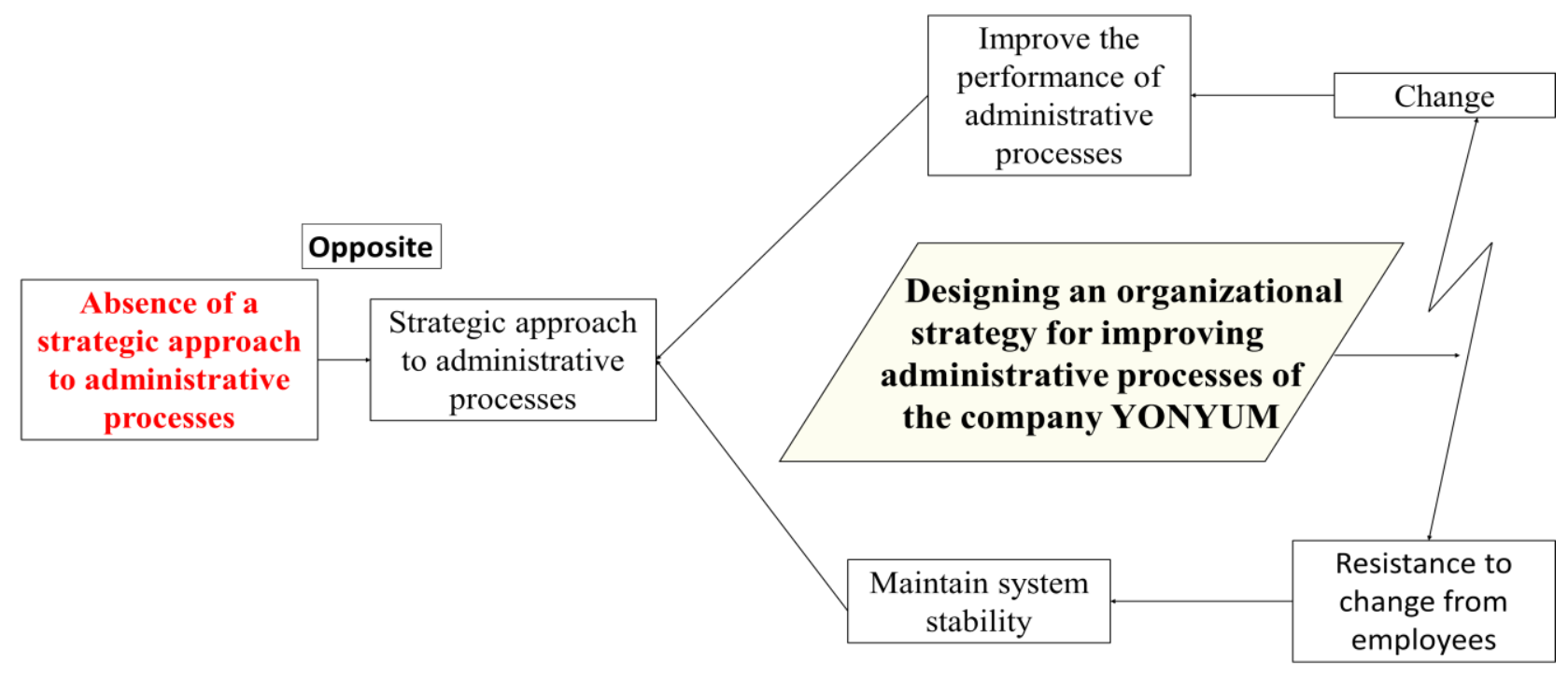

Figure 5: Construction and evaporation of the cloud of organizational conflict

As one can see, it was necessary to formulate another support strategy to achieve the vision of administrative processes. Finally, two strategies are formulated, the first and essential and commented: "Designing an organizational strategy for improving administrative processes of Yonyum Company" and the second support, "Designing participation mechanisms."

Step 4: Setting goals and action plans

Construction Tree allows Prerequisites present how to be disaggregating the strategy formulated by identifying obstacles and intermediate objectives to be implemented for implementation. To achieve the objective of this step the group activity was developed with the following work plan:

1. Objective: Build the Prerequisites Tree and Tree of Transition.

2. Methodology: procedure for the construction of Prerequisite Tree and Tree of Transition. With auxiliary materials such as: flipcharts, markers and post-it.

3. Time available: two working sessions of two hours.

Knowing this, the strategies formulated begin to identify obstacles to implementation possible intermediate targets that would allow eliminating, so the logic would be if person reaches the intermediate target, removing the obstacle and it is possible to implement the strategy. The result of teamwork to Prerequisites Tree can be seen in Figure 7.

The actions planned to achieve the objectives corresponding to the implementation of the strategies formulated take the form of an action plan which, being consistent with the theoretical position that was assumed in this research strategy and plan constitutes the strategy of improving administrative processes of Yonyum Company. The detailed plan is shown in Table 1.

The tendency to change that present the variables analyzed and the time between diagnosis and implementing solutions may potentiate the genesis of new obstacles on the planned actions, justifying the implementation of measures of adjustment. Likewise, in order to ensure the improvement of administrative processes, it is necessary to establish mechanisms to monitor the evolution of the implementation and results of the actions planned in time. In this sense, the organization shall establish an evaluation system and the behavior of the variables which is subject, said control system must act periodically to check the evolution of the system and its timely adjustment; corresponding application to the top leadership of the organization. 


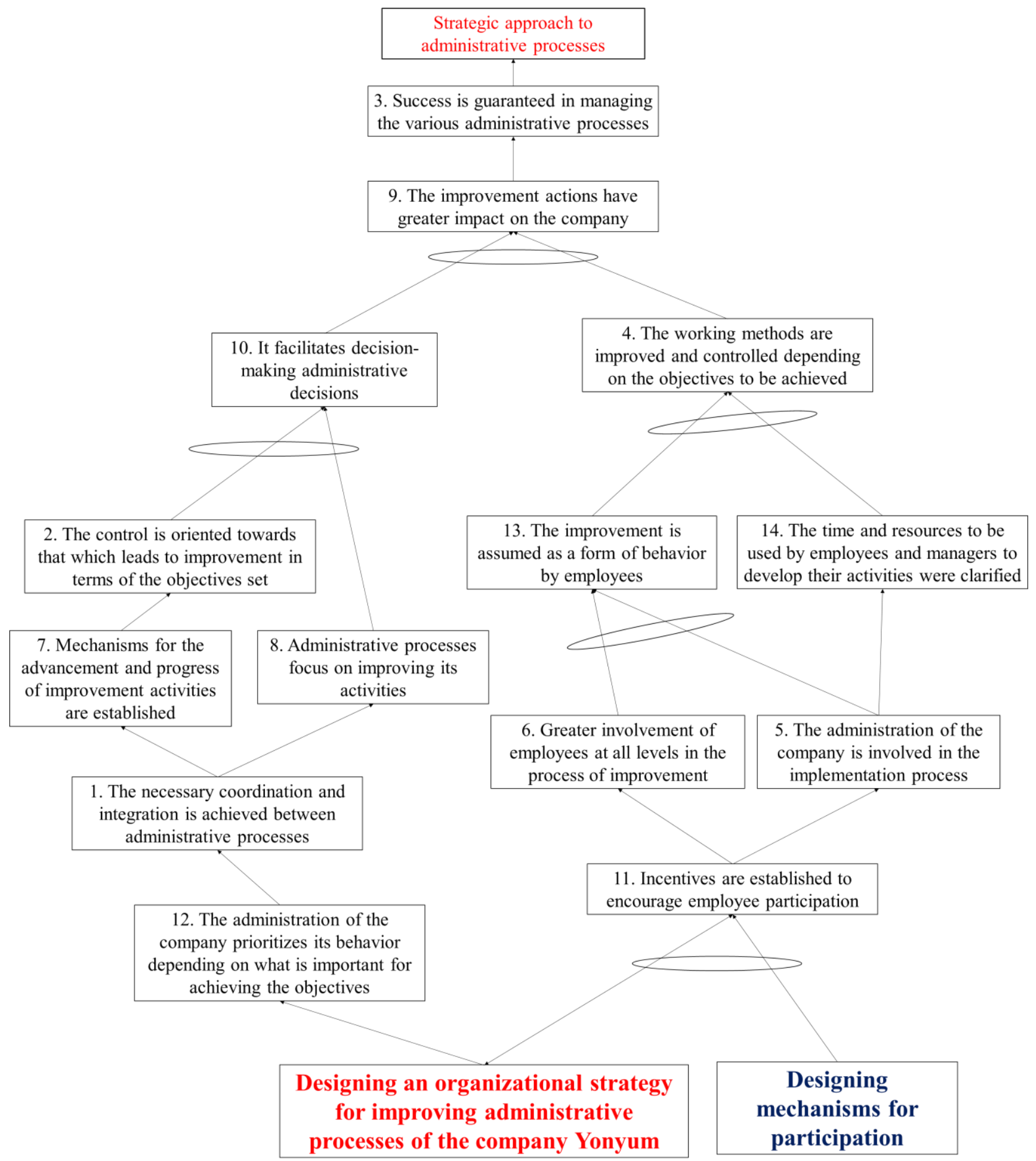

Figure 6: Future Reality Tree

The analysis of this instrument of thought processes four intermediate objectives to be achieved to implement the strategies developed leaves identified. To achieve these objectives, it is necessary to plan a series of actions leading to these results, which, as discussed earlier, will allow the implementation of strategies that Tree of Transition is shown in Figure 8 . 


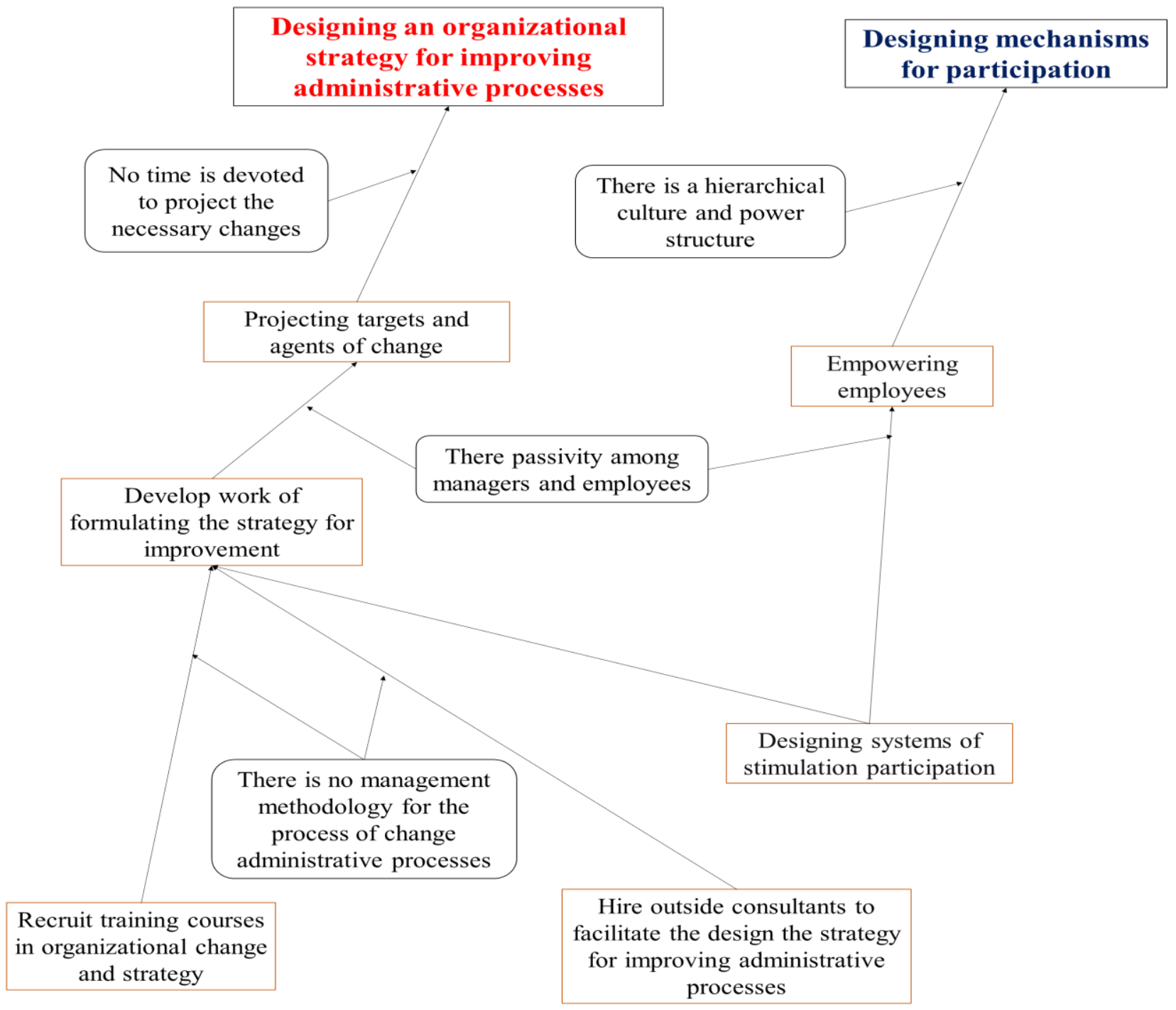

Figure 7: Tree of Prerequisites

Table 1: Parameters and variables for evaluation

\begin{tabular}{|l|l|}
\hline \multicolumn{1}{|c|}{$\begin{array}{c}\text { Characterizing } \\
\text { parameters }\end{array}$} & \multicolumn{1}{|c|}{ Possible variants to happen } \\
\hline \multirow{4}{*}{ P.1. Market } & $\begin{array}{l}\text { P.1.1. Growing market, where the company is inserted successfully in the } \\
\text { market with strong growth and recognition that improves its positioning. }\end{array}$ \\
\cline { 2 - 3 } & $\begin{array}{l}\text { P.1.2. The stable market, where the company does not improve and maintain } \\
\text { its status quo. }\end{array}$ \\
\cline { 2 - 2 } $\begin{array}{l}\text { P.1.3. It decreases market, where the company worsens their current } \\
\text { situation. }\end{array}$ \\
\hline \multirow{5}{*}{ P.2. Employees } & $\begin{array}{l}\text { P.2.1. Growing internal satisfaction, job satisfaction is increased by } \\
\text { improving the disposal company to generate improvement processes. }\end{array}$ \\
\hline & $\begin{array}{l}\text { P.2.2. Sustained internal satisfaction, employee satisfaction shows no } \\
\text { significant changes }\end{array}$ \\
\cline { 2 - 3 } P.3. Objectives & $\begin{array}{l}\text { P.2.3. Internal satisfaction worsens, manifesting a state of anomie in the } \\
\text { company contributing to its deterioration }\end{array}$ \\
\hline & $\begin{array}{l}\text { P.3.1. Objectives improvements, organizational goals efficiently and } \\
\text { effectively be achieved }\end{array}$ \\
\cline { 2 - 2 } & $\begin{array}{l}\text { P.3.2. Objectives are not achieved, and there is a process of deterioration in } \\
\text { the company }\end{array}$ \\
\hline
\end{tabular}




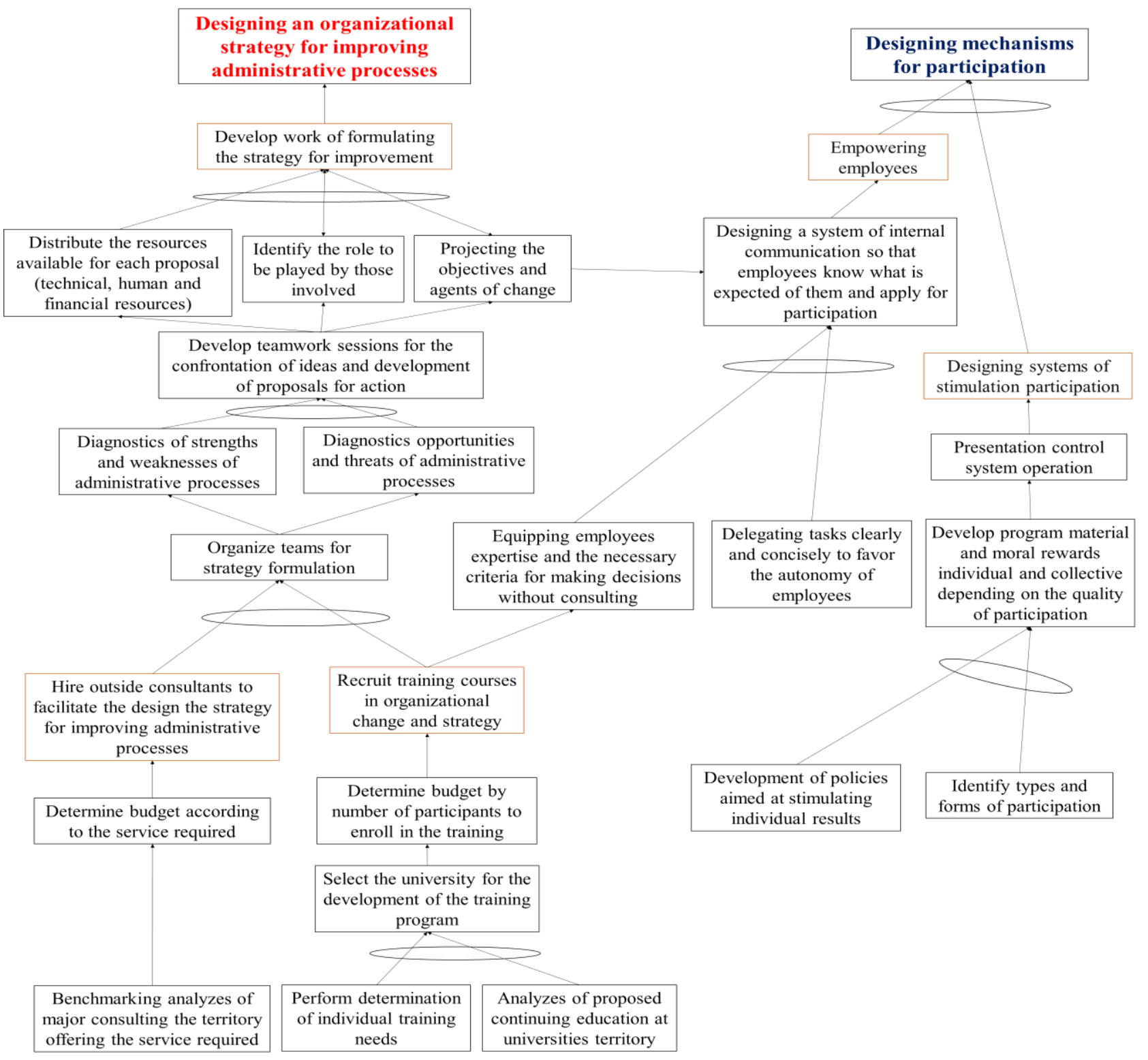

Figure 8. Tree of transition

In order to know whether the proposal made will have the desired impact on the company, we studied proceeded to perform a morphological analysis (Zwicky, 1969) which allows visualizing the future status of administrative processes. The results obtained are shown in Figure 8.

The central idea is to visualize how Yonyum Company will behave once applied the strategy of improving administrative processes in terms of the negative aspects that were illustrated in the approach to the problem that gave rise to the inquiry: (1) market growth (2) dissatisfactions of employees and (3) Compliance with the objectives, within three (3) years. As is stated the problem, there are (in the lexicon of the art) three (3) characterizing parameters: P.1. Market; P.2. Employees; and P.3. Objectives.

Of these three (3) parameters, and their respective variants in each, the number of possible scenarios to be considered in the course of trying to visualize the future enterprise Yonyum, which is derived in the case that we are concerned behaves the way that follows $3 * 3 * 2$ for a total of 18 possible scenarios.

They represent all possible variants we may arise in relation to the factors considered and their respective modes of interest for each factor, allowing build Multidimensional Matrix (Table 2), which facilitates the identification of each possible scenario. 
Table 2: Matrix Multidimensional

\begin{tabular}{|c|c|c|c|}
\hline Characterizing parameters & \multicolumn{3}{|c|}{ Possible variants to happen } \\
\hline Market & Market grows & Stable market & Market decreases \\
\hline Employees & $\begin{array}{c}\text { Internalsatisfactiongro } \\
\text { ws }\end{array}$ & $\begin{array}{c}\text { Sustainedinternalsatisfact } \\
\text { ion }\end{array}$ & $\begin{array}{c}\text { Internalsatisfaction } \\
\text { worsens }\end{array}$ \\
\hline Objectives & \multicolumn{2}{|c|}{ Objectivesimprove } & Objectives are notachieved \\
\hline
\end{tabular}

The 18 previously mentioned scenarios are formed with some combination of the possible variants happen shown in Table 3. Each of these scenarios can be represented in the form:

Scenario $_{n}\left\{\begin{array}{c}\text { Market }_{p 1 n} \\ \text { Satisfaction }_{p 2 n} \\ \text { Objectives }_{p 3 n}\end{array}\right\}$

After obtaining the likely future scenarios as a result of the application of Morphological Analysis, it proceeds to the application of the Delphi method to make estimates of the probabilities of occurrence of each of the proposed scenarios. In this case particularly, it is clear three (3) questions about an uncertain future:

1. What type of behavior will market Yonyum Company?

2. What level of satisfaction will employees of Yonyum Company?

3. Improve or not meeting the objectives of Yonyum Company?

Table 3: Results of the questionnaire application

\begin{tabular}{|c|c|c|c|c|c|}
\hline \multirow{9}{*}{$\underset{\Xi}{\stackrel{\Xi}{\Xi}}$} & $\begin{array}{c}\text { Characterizing } \\
\text { parameters }\end{array}$ & $\begin{array}{c}\text { Possible variants to } \\
\text { happen }\end{array}$ & No. & $\begin{array}{c}\text { Ordinaryfrequency } \\
\text { response }\left(f_{i}\right)\end{array}$ & Rrelativefrequency $\left(h_{i}\right)$ \\
\hline & \multirow{3}{*}{ P.1. Market } & Marketgrows & 1 & 4 & 0,66 \\
\hline & & Stablemarket & 2 & 1 & 0,17 \\
\hline & & Marketdecreases & 3 & 1 & 0,17 \\
\hline & \multirow{3}{*}{ P.2. Employees } & Internalsatisfactiongrows & 1 & 5 & 0,83 \\
\hline & & Sustainedinternalsatisfaction & 2 & 1 & 0,17 \\
\hline & & Internalsatisfactionworsens & 3 & 0 & 0,00 \\
\hline & \multirow{2}{*}{ P.3. Objectives } & Objectivesimprove & 1 & 4 & 0,66 \\
\hline & & Objectives are notachieved & 2 & 2 & 0,34 \\
\hline
\end{tabular}

From these questions, a "questionnaire model" consisting of questions with nominal scales, to be used in the exercise Delphi and will serve to carry out the execution of the working group that had been developing the work was produced. After making the process the following results:

The next step is the interpretation of the results within the context of each parameter; ie partial scenarios for each parameter descriptive, because the processing of the results becomes much easier and manageable in practical terms to analyze the 18 scenarios with all combinations (Zwicky, 1969). For this analysis criterion, Table 4 is used.

In the context of these findings, it can be summarized that, based on the judgments of experts, in specified scenarios: the market, internal employee satisfaction, and organizational goals gave more likely $60 \%$ considered a high probability scenario so we can build an exploratory stage and that "shows" each of the aspects (parameters descriptors) considered. The description of this scenario: 
"Yonyum Company is inserted successfully in the market with strong growth and recognition that improves its positioning based on increased job satisfaction of its employees thereby improving their willingness to generate improvement processes and achieve objectives the organization efficiently and effectively."

The scenario described above would improve the situation of the company in its industry and thus could alleviate the absence of barriers to entry (competitors) to the sector, as the smooth running of the company would impose standards to new competitors that could serve as competitive barriers for entering the market. Likewise, the situation would behave when the threat of entry of substitute products, which continue to exist and probably proliferate, but the effective functioning of the administrative processes within the company, could bring the company product Yonyum out the market with a better chance to compete.

Table 4: Criteria for interpreting results

\begin{tabular}{|c|c|l|}
\hline No. & Scenario & \multicolumn{1}{c|}{ Interpretation } \\
\hline 1 & $\begin{array}{c}\text { Probable scenarios } \\
\text { (high probability) }\end{array}$ & $\begin{array}{l}\text { A scenario is considered "probable" when the probability of occurrence (in } \\
\text { the opinion of experts) of each of the modalities of its characterizing } \\
\text { parameters is greater than } 0.60, \text { i.e., } 60 \% .\end{array}$ \\
\hline 2 & $\begin{array}{c}\text { Improbable scenarios } \\
\text { (low potential) }\end{array}$ & $\begin{array}{l}\text { A scenario is considered "improbable" when the probability of occurrence } \\
\text { (in the opinion of experts) of each of the modalities of its characterizing } \\
\text { parameters is less than 0.40, i.e., 40\%. }\end{array}$ \\
\hline 3 & $\begin{array}{c}\text { Uncertain scenarios } \\
\text { (uncertainty) }\end{array}$ & $\begin{array}{l}\text { A scenario is considered "uncertain" when it is neither «probable» nor } \\
\text { "improbable"; i.e., not qualify in any of the above categories. }\end{array}$ \\
\hline
\end{tabular}

Based on the results in Table 4 and the criteria set out in Table 5 the following result can be seen:

Table 5: Variables that characterize the dominant scenario

\begin{tabular}{|c|c|c|l|}
\hline $\begin{array}{c}\text { Characterizing } \\
\text { parameters }\end{array}$ & Domination scenario & Relative frequency(hi) & \multicolumn{1}{|c|}{ Conclusions } \\
\hline P.1. Market & Market grows & 0,66 & $\begin{array}{l}\text { The company is inserted } \\
\text { sucessfully in the market } \\
\text { with strong growth and } \\
\text { recognition that improves its } \\
\text { positioning }\end{array}$ \\
\hline P.2. Employees & Internalsatisfactiongrows & 0,83 & $\begin{array}{l}\text { It increases job satisfaction in } \\
\text { the company by improving the } \\
\text { arrangement for generating } \\
\text { improvement processes }\end{array}$ \\
\hline P.3. Objectives & Objectivesimprove & $\begin{array}{l}\text { The objectives of the } \\
\text { organization are achieved } \\
\text { efficiently and effectively }\end{array}$ \\
\hline
\end{tabular}

If the company improves its administrative processes to involve under the new scenario, a company will strengthen internally, allowing better projection into the market so it could increase their bargaining power with suppliers as a company distinguished to which providers as a customer would be worth serving and serve. From the standpoint of bargaining power of consumers Needless to say, by the large supply in the market consumers will continue to have great power, however, a business strengthened by the proper functioning of its administrative processes could focus on impregnating an added value to their products, differentiating them on the market, which could give some advantage for consumers getting their preference of them in the market and thus improving their positioning.

All this would allow the company to be in a better position to compete with existing companies offering in the market, and although the rivalry persists, Yonyum will be better able to face such competition. The results and forecasts 
presented above allow to state that the proposal made to Yonyum Company, may be valid to enable it to improve its administrative processes and thus, mitigate the issues presented today.

\section{Conclusion}

1) The scope of the theory of both strategic management, administrative processes and continuous improvement, making a contribution to the administrative science and in turn providing guidelines and guidance to researchers continue to address these issues or who wish to apply is discerned the strategy proposed for Yonyum Company.

2) It has achieved the required address by analyzing the approach of the strategy to propose better strategy type required to meet the target of the investigation.

3) To avoid the impact that the company may face depending on the change that causes implement the strategy of the action plan, it was conducted using the methodology of thinking processes.

4) After get to know the real situation of the organization and its problems in a holistic sense in their administrative processes an action plan that provides solutions to these problems developed, based on two strategies, the first and essential: "Designing an organizational strategy to improve the administrative processes of Yonyum Company", and the second in support: "Designing participation mechanisms".

5) Based on the opinion of experts concluded that in scenarios: the market, internal employee satisfaction and organizational goals gave more likely $60 \%$ considered a scenario of high probability, so that you can thus build up an exploratory stage displaying each of the descriptors parameters considered, as follows: "Yonyum Company is inserted successfully in the market with a strong growth and recognition that improves its positioning based on increased job satisfaction It is allowing employees to improve their willingness to generate improvement processes and achieve organizational goals efficiently and effectively".

6) The impact of implementing the strategy will yield better performance in the administrative processes of the company that will strengthen considerably improving the situation of the company in its industry, which could alleviate the absence of barriers to entry to the sector, the smooth running of the company to new competitors would impose standards that could serve as competitive barriers to entering the market. Likewise, the situation would behave when the threat of entry of substitute products, but the effective functioning of the administrative processes within the company, could bring the company product Yonyum hit the market with a better chance to compete.

\section{References}

- Chou, Y.-C., Lu, C.-H., and Tang, Y.-Y. (2012). Identifying inventory problems in the aerospace industry using the theory of constraints. International Journal of Production Research, 50(16), 4686-4698, CrossRef

- Cox, J. F., and Spencer, M. S. (1998). The Constraints Management Handbook. Boca Raton, FL.: St Lucie Press / APICS Series on Constraints Management.

- Cox, J. F., Blackstone, J. H., and Schleier, J. G. (2003). Managing operations: A focus on excellence. Great Barrington, MA: North River Press.

- Dettmer, H. W. (1997). Goldratt's Theory of Constraints: A Systems Approach to Continuous Improvement. Milwaukee, WI.: ASQC Quality Press.

- Gupta, M. (2003). Constraints management: recent advances and practices. International Journal of Production Research, 41 (4), 647-659, CrossRef

- Gupta, M. C., Boyd, L. H., and Sussman, L. (2004). To better maps: a TOC primer for strategic planning. Business Horizon, 47 (2), 15-26, CrossRef

- Kendall, G. I. (1998). Securing the Future: Strategies for Exponential Growth Using the Theory of Constraints. Boca Raton, FL.: St. Lucie Press / APICS Series on Constraints Management.

- Klein, D. J., and Debruine, M. (1995). A Thinking process for establishing management policies. Review of Business, 16 (3), 37-42.

- Mabin, V. J., and Balderstone, S. J. (1999). The World of the Theory of Constraints: A Review of the International Literature. Boca Raton, FL. : St. Lucie Press / APICS Series on Constraints Management.

- McMullen, T. B. (1998). Introduction to the Theory of Constraints (TOC) Management System. Boca Raton, FL.: St. Lucie Press/ APICS Series on Constraints Management.

- Noreen, E., Smith, D. A., and Mackey, J. T. (1995). The Theory of Constraints and its Implications for Management Accounting. Great Barrington, MA.: The North River Press Publishing Corporation. 
- Schragenheim, E., and Dettmer, H. W. (2000). Manufacturing at Warp Speed: Optimizing Supply Chain Financial Performance. Boca Raton, FL: St. Lucie Press, APICS.

- Taylor, L. J., and Ortega, R. D. (2003). The application of Goldratt's thinking process to problem-solving. Proceedings of the Academy of Strategic Management, 2(2), 9-14.

- Tulasi, C. L., and Rao, A. R. (2012). Review on the theory of constraints. International Journal of Advances in Engineering and Technology, 3(1), 334-344.

- Valle Antunes, J. A., Klippel, M., Koetz, A. L., and Pacheco Lacerda, D. (2004) . Critical Issues about the Theory Of Constraints Thinking Process - A Theoretical and Practical Approach. Paper presented at the Second World Conference on POM and 15th Annual POM Conference.

- Watson, K. J., Blackstone, J. H., and Gardiner, S. C. (2007). The evolution of a management philosophy: The theory of constraints. Journal of Operations Management, 25 387-402, CrossRef 